\title{
A música eletroacústica na escola: delineando perspectivas sob a abordagem sociocultural da educação musical
}

\author{
Daiane Solange Stoeberl da Cunha (Universidade Estadual Paulista e Universidade Estadual do Centro- \\ Oeste, Guarapuava, Paraná, Brasil) \\ dai_flc@yahoo.com.br
}

\begin{abstract}
Resumo: Este artigo apresenta a perspectiva sociocultural da educação musical como importante instrumental para a análise da música na cultura escolar. Tem como foco a discussão sobre aspectos desta abordagem teórica aplicados à temática do ensino de música eletroacústica na escola. Dentre os autores que fundamentam esta reflexão destacam-se: Geertz (1989), Tia DeNora (2000), Arroyo (2002, 2013), Green (1997, 2012), Small (1999), Stockfeld (1997), Elliott (1995), Jorgensen (1997), Allsup (2010). Propõem-se argumentos para compreender os desafios e as possibilidades do fazer docente diante de um repertório musical inovador.
\end{abstract}

Palavras-chave: Educação musical; Perspectiva sociocultural; Música eletroacústica; Educação básica.

The electroacoustic music in the school: outlining perspectives under the sociocultural approach of musical education Abstract: This article presents the sociocultural perspective of music education as an important instrument for the analysis of music in school culture. It focuses on the discussion about aspects of this theoretical approach applied to the theme of teaching electroacoustic music in schools. Among the authors that base this reflection we highlight: Geertz (1989), Tia DeNora (2000), Arroyo (2002, 2013), Green (1997, 2012), Small (2009), Stockfeld (1997), Elliott (1995), Jorgensen (1997), Allsup (2010). Finally, we suggest some arguments to comprehend the challenges and possibilities of teaching face to an innovative musical repertoire.

Keywords: Musical education; Sociocultural Perspective; Electroacoustic Music; Basic education.

Pensar sobre o ensino de música eletroacústica pressupõe reflexão no âmbito da própria música, considerando sua história, estética e técnica; da sociologia, que contempla transformação social, tecnológica e econômica; da antropologia, que discute sobre cultura, relações humanas e mecanismos culturais; e, no âmbito da educação, por meio da didática, das metodologias e dos fundamentos pedagógicos e filosóficos que a regem. Diante de tantos aspectos que envolvem o fazer didático-musical do repertório musical, seja ele popular, seja erudito, tradicional ou contemporâneo, apresento uma reflexão inicial firmada na perspectiva sociocultural da educação musical, que tem sua base conceitual assentada na sociologia e na antropologia, para compreender questões sociais e culturais na construção da aprendizagem musical.

O enfoque na música eletroacústica se dá pelo meu interesse em compreender a produção e o ensino deste gênero musical que é pouco conhecido pela sociedade em geral, sendo parte apenas de uma comunidade restrita de músicos eruditos. Entretanto, intriga-me o fato de que as técnicas e tecnologias utilizadas para a composição eletroacústica, ainda que com outra funcionalidade e estética, aproximam-se cada vez mais da realidade das crianças e dos jovens. O meio digital e as tecnologias computacionais estão presentes nas produções musicais populares, na rádio, na televisão, no cinema, nos bailes, baladas e raves, assim como nos celulares e, consequentemente, no ambiente escolar, ainda que de maneira informal. Entretanto, as práticas de ensino musical engessadas por preconceitos e conservadorismo, muitas vezes, são afastadas das transformações tecnológicas e mantêm as práticas de ensino musical voltadas apenas para o repertório tradicional, alienando-se desta importante produção musical contemporânea que revela e reflete a cultura pós-moderna. 
Ao passo que a educação musical se mantém, muitas vezes, aquém da produção musical contemporânea, as transformações no contexto composicional musical ocorrem em simultaneidade com as transformações sociais:

Desde a antiguidade, a produção musical foi determinada pela tecnologia disponível e a cultura em que foi concebida. Isto não foi diferente ao longo do século XX, quando observamos que a música e a paisagem sonora da sociedade atual, limitadas pelos sons pós-industriais - os quais refletem, por sua vez, as transformações e impactos da Revolução Industrial e Elétrica -, evidenciam, por exemplo, o ruidismo das máquinas e novas concepções no âmbito da textura. Todos esses aspectos emergem como resultado da ampliação do próprio conceito de material musical, a partir do momento em que são inseridas nas composições qualidades sonoras complexas que foram classificadas durante longo tempo na categoria de 'ruído' (CUNHA; GALLO, 2014, p. 117).

A produção musical eletroacústica teve sua origem influenciada pela música concreta, com as possibilidades de gravação e manipulação de sons para criação musical. Tal gênero foi mediado por Pierre Schaeffer (1910-1995), com sons captados e gravados em fitas magnéticas, e também pela música eletrônica, preconizada por Herbert Eimert (1897-1972), com a produção de sons através do uso do computador e de um gerador de sinais para seu ato criativo. A eletroacústica é parte da cultura pós-moderna, pois "[...] a partir do século $\mathrm{XX}$, o campo sonoro tonal, que se caracterizava pela filtragem dos ruídos, entra em desequilíbrio, e ruídos de todos os tipos passam a ser considerados matéria-prima da música” (CUNHA; GOMES, 2014, p. 107). Segundo Koellreutter (1990, p. 10), trata-se do "[...] reflexo de nossa vida cotidiana e a vida é transformação constante [...]. É preciso compreender que a humanidade deve concentrar todos os seus esforços nesse processo de transformação constante, pois é este que constitui o único aspecto inalterável de nossa existência”.

A sociedade do século XXI está impregnada pela cultura pós-moderna, na qual a rapidez da inovação tecnológica acompanha a dissolução de paradigmas modernos. À imagem da sociedade, a música, assim como as demais manifestações artísticas dos séculos XX e XXI, transforma-se rapidamente. A sociedade contemporânea apresenta a necessidade de uma revisão dos paradigmas epistemológicos que provocam a fragmentação cognitiva e a excessiva racionalidade. Os fundamentos da sociologia cultural trazem à tona o pensamento pós-moderno na quebra de paradigmas modernos do pensamento linear de causa e efeito outrora legitimados, propondo a compreensão do conhecimento enquanto teia de significados. Geertz ${ }^{1}$, fundamentado na semiótica, define o comportamento humano como essa ação simbólica que gera a teia cultural:

[...] o homem é um ser amarrado à teia de significado que ele mesmo teceu, assumo a cultura como sendo estas teias e sua análise, portanto, não como uma ciência experimental em busca de leis, mas como uma ciência interpretativa, à procura do significado (GEERTZ, 1989, p. 15).

Ao refletir sobre cultura, educação e música, a partir de um olhar da sociologia cultural, é necessário repensar e desconstruir paradigmas estabelecidos na modernidade. Para Maffesoli² (2010), a matriz social moderna tornou-se infecunda e saturada, contrapondo-se à ideia de Max Weber de desencantamento do mundo. A ideia de saturação está na relação íntima entre destruição e reconstrução, o que ocorre com as pedras fundamentais da modernidade: razão, individualismo, economia e progresso.

Enquanto na modernidade se pensava e trabalhava com a noção de isto ou aqui- 
lo, como uma perspectiva dicotômica que se aplicava às ideias, ao gosto, às escolhas e às ações, a pós-modernidade desconstrói esse paradigma do $o u$, substituindo-o pela compreensão conjuntiva de isto e aquilo e, ainda, isto com aquilo, e ampliando as formas de relações e admissão de opostos se atraindo. Para compreender melhor essa mudança paradigmática, tomo como exemplo a definição de um repertório musical centrado apenas no popular ou no erudito, ou seja, práticas musicais que eram centradas apenas em tocar de ouvido ou pela leitura de partitura. Na pós-modernidade, admite-se que um músico toque, estude e goste de repertórios variados - do erudito ao popular -, utilizando-se de recursos de aprendizagem diversos que lhe forem mais apropriados a cada momento e repertório. Neste pensamento, o educador musical pós-moderno amplia o repertório de suas aulas, inserindo práticas de apreciação, performance e criação nas mais variadas estéticas musicais, somando à música tradicional a étnica, a experimental e também a eletroacústica. Há que se contemplar na transformação da abordagem pedagógica a utilização tanto de instrumentos musicais da tradicional bandinha rítmica quanto da percussão corporal, dos instrumentos sinfônicos e, também, o celular e o computador, além de outros aparatos eletrônicos e digitais.

O pensamento moderno pode ser notado ainda, com grande ênfase, em relação à postura do educador musical diante do repertório tradicional ou contemporâneo. Essa necessidade de optar por apenas um gênero musical está presente nas universidades, conservatórios e nos diversos ambientes em que o fazer didático musical está presente. Trata-se de uma questão cultural que permanece enraizada nesses ambientes educacionais que herdaram a concepção de ensino-aprendizagem cartesiano e positivista, além da definição de conteúdos ensináveis centrados na música de concerto europeia dos séculos XVIII e XIX (ARROYO, 2002)

Coadunando com o pensamento pós-moderno, Estelle Jorgensen ${ }^{3}$ sugere pares de conceitos nos quais um está dialeticamente relacionado ao outro. Cada par constitui-se num dilema para a educação musical. São eles: forma musical e contexto; grandes e pequenas tradições; transmissão e transformação; continuidade e interação; making e receiving, traduzidos literalmente por "criando e recebendo" ou "criar e receber”; filosofia e prática, dentre outros (JORGENSEN, 1997).

Diante dessas simultaneidades, está claro que as transformações nas produções musicais suscitam mudanças educacionais. É fato que o desenvolvimento tecnológico exerce grande influência na composição musical atual, tanto nos meios de produção quanto na estética musical, além de o desenvolvimento social, econômico e tecnológico instigar mudanças no ensino de música. Para educadores musicais contemporâneos como Murray Schafer (2009, 2011a, 2011b), Guy Reibel (1984) e Swanwick (2011), é essencial que a formação musical seja adequada à realidade de sua época.

Para Marisa Fonterrada, há uma tendência atual por parte dos educadores musicais da segunda metade do século XX de inserirem música nova no ensino musical e incorporarem procedimentos dos compositores vanguardistas à educação musical. A autora sugere que esse ensino deve privilegiar "[...] a criação, a escuta ativa, a ênfase no som e suas características, e evitando a reprodução vocal e instrumental do que denominam 'música do passado"” (FONTERRADA, 2008, p. 179).

A música contemporânea apresenta-se como um idioma musical em constante inovação que aborda poéticas artísticas pós-modernas e contempla uma nova estética sonora que se caracteriza pela investigação timbrística, apropriando-se das mais diferenciadas tecnologias, técnicas e materiais. As produções musicais contemporâneas ultrapassam os limites da área musical e, cada vez mais, se inter-relacionam com as demais linguagens 
artísticas. A contemporaneidade é um momento de simultaneidade de ideias, criações e práticas artístico-pedagógicas. Margarete Arroyo, em seu texto intitulado "Educação musical na contemporaneidade" define o termo:

Tomo por contemporaneidade "o hoje" ou o bem próximo do hoje, ou ainda, o que parte de nós educadores musicais e/ou pesquisadores temos pensado e realizado no momento. Entretanto, é preciso estar ciente de que esse pensamento e essa ação estão assentados sobre um processo de construção de ideias e práticas, isto é, sobre uma história que vem influenciando a área da Educação Musical (ARROYO, 2002, p. 18).

Neste sentido, a produção musical contemporânea é vasta e diversificada, com a qual o educador musical pode desenvolver práticas de apreciação, composição e performance e permitir que o aluno desenvolva sua autonomia nos diferentes pares dialéticos: o antigo com o novo, o mecânico com o digital, o acústico com o eletrônico, o popular com o erudito.

Arroyo também alerta para que, ao considerarmos a perspectiva sociocultural como fundamento para compreendermos a contemporaneidade, isso

[...] implica em considerarmos que toda prática musical, "fenômeno transversal”, que "perpassa todos os espaços sociais" (Bozon, 2000, p.147), traz implícita a aprendizagem dessa prática e que, assim, alguma modalidade de educação musical ocorre em diversos contextos, envolvendo grupos sociais e culturais diversos (ARROYO, 2002, p. 18).

Como bem observado por Arroyo, a aprendizagem musical é ação social e cultural e, como tal, ocorre nos diferentes espaços sociais de diferentes maneiras. Os processos de aprendizagem informais, por exemplo, têm sido estudados a fim de serem compreendidos e adotados, ainda que sistematicamente, por educadores musicais.

Contudo, há um grande distanciamento entre o repertório musical dos séculos XX e XXI e a educação musical. Esse fato tem motivado educadores a pesquisar e desenvolver encaminhamentos possíveis à realidade brasileira e essas pesquisas partem da problemática da ausência de repertório e, ainda mais, da ausência de metodologias de ensino de música contemporânea para o ambiente escolar.

Há tempos, observo a ausência da música contemporânea na escola e percebo que há pouco interesse por parte dos educadores musicais em inseri-la em seus planejamentos. Álvaro Borges, ao realizar sua tese de doutorado, deparou-se com a mesma problemática:

[...] a realidade observada demonstrou que os alunos não tinham acesso ao repertório de música contemporânea, tanto experimental quanto eletroacústica. Constatou-se também que, na mesma proporção, os educadores não apresentavam conhecimentos específicos que pudessem favorecer a abordagem deste repertório. Em vista dessas circunstâncias, ressaltou-se, portanto, a preocupação do pesquisador em relação às formas de acesso dos educadores e dos seus alunos à música ao pensamento musical da atualidade (BORGES, 2014, p. 15).

Em condições similares, a educadora musical Leila Vertamatti (2008, p. 16) assinala a pouca vivência das crianças e jovens no que se refere ao repertório da chamada música contemporânea.

Esta realidade aponta para uma grande demanda de estudos, desafios e possibilidades para o educador musical diante da produção musical hodierna. Ressalto que meu contato com a perspectiva sociocultural da educação musical permitiu-me vislumbrar outras 
possibilidades de compreender as relações que se estabelecem entre os sujeitos da educação musical. Nelas, estão imbuídas relações de gosto, de tradições, de pensamento filosófico e pedagógico.

As características da abordagem sociocultural da educação musical expostas por McCarthy ${ }^{4}$ (2002) apresentam a incorporação da diversidade de valores musicais, sociais e culturais dos agentes da educação, tanto estudantes quanto professores. A aprendizagem e o ensino de música são compreendidos como processos permeados por valores e significados culturais e sociais. Neste sentido, o repertório musical apresentado às crianças nas classes de educação musical é definido pela cultura dos sujeitos da educação: docentes e discentes. Nesta perspectiva, a horizontalidade na relação entre esses sujeitos promove a aprendizagem mútua, numa troca de valores. Aprender e praticar música são ações culturais, consequentemente, a educação musical e a performance musical podem incorporar a diversidade de valores musicais, sociais e culturais dos estudantes e músicos. Para McCarthy, professores e alunos exercem mutuamente a construção da concepção de música e isto pode ser viabilizado por meio de currículos democráticos que deem acesso universal à educação musical básica, na construção coletiva do currículo e na ampliação de conteúdos diferenciados.

O objetivo das pesquisas fundamentadas na perspectiva sociocultural está no desvelamento e na interpretação dos elementos contextuais que fornecem uma explicação social e cultural dos processos de transmissão da música (GREEN, 1997). Entendemos que o melhor termo para transmissão da música, na perspectiva adotada neste ensaio, é a aprendizagem musical, considerando que aprendizagem é a palavra central no campo teórico-prático da educação musical.

Para Lucy Green ${ }^{5}$, o estudo sociológico da música pode auxiliar tanto na compreensão sobre a organização social das práticas musicais, quanto sobre a construção social do significado musical. De acordo com Green (1997, p. 27), a sociologia da música "interessa-se por grupos sociais e suas interfaces com a produção, distribuição e receptividade musicais. Em suma, eu me referirei a essa área como sendo ‘a organização social da prática musical’”.

Nesta perspectiva, pautamo-nos na teoria relativa aos significados musicais de Lucy Green para pensar em uma educação musical mais abrangente. Esta pesquisadora do campo da sociologia da educação musical fundamenta-se nos questionamentos feitos pela sociologia aos significados das coisas e propõe:

[...]deve-se questionar o grau de acordo ou desacordo acerca desses significados, como velhos significados são reproduzidos e novos gerados. Similarmente, em Música questionamos os significados da música que um grupo social produz, distribui e consome, quais são esses significados e como eles são construídos, mantidos e questionados. Para mim, um aspecto fundamental na Sociologia da música é o compromisso de apreciar ambos os lados - a organização social da política musical e a construção social do significado musical. Do contrário, estaríamos nos furtando de alguns dos mais importantes e interessantes aspectos do âmago do estudo (GREEN, 1997, p. 27).

Green também propõe uma distinção entre dois aspectos do significado musical: os significados inerentes ou intrassônicos, que consistem nas inter-relações dos materiais sonoros, e os significados delineados, que são os fatores simbólicos do significado musical. Na interação entre os significados inerentes e os delineados é que reside o desafio à educação musical. Vejamos o organograma a seguir: 


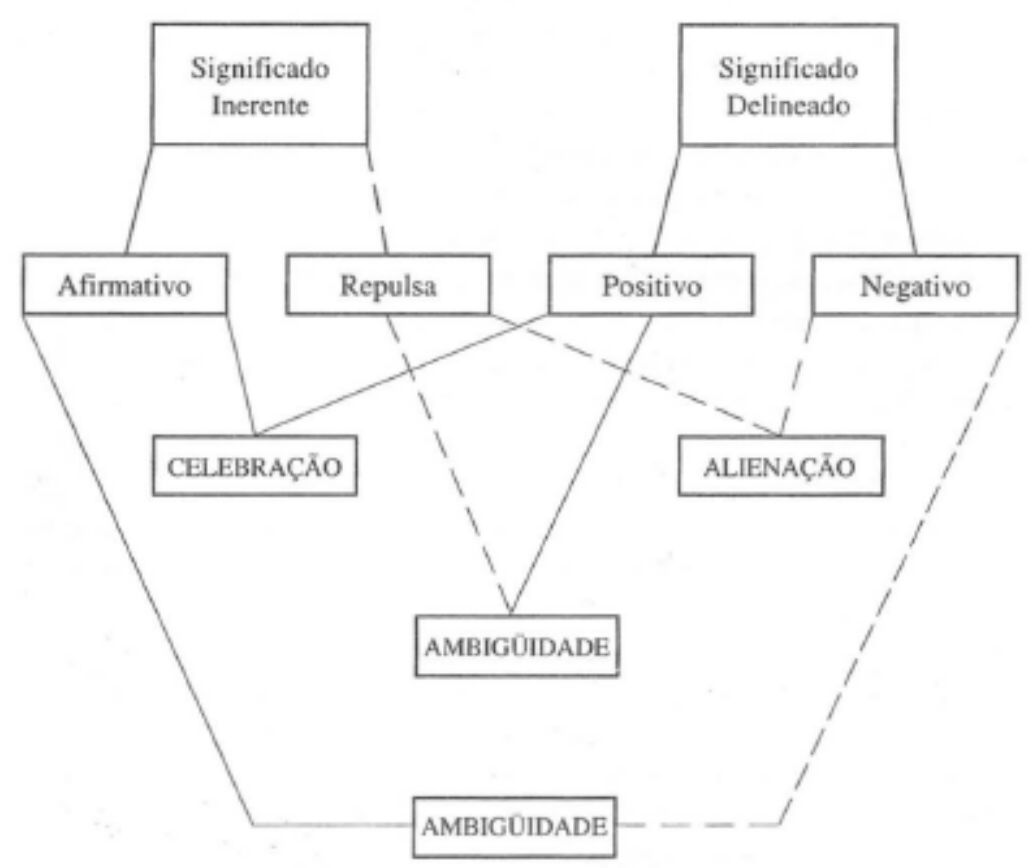

Figura 1: Infográfico proposto por Lucy Green: Significado Inerente e Delineado

Fonte: Green (1997, p. 27).

A construção do significado musical se dá na experiência musical a qualquer tempo, lugar e circunstância. Podemos compreender como a interação dos significados ocorre, por exemplo, em uma aula sobre música contemporânea numa sala de aula de educação musical de uma escola de educação básica, na qual o professor sugerisse a apreciação da peça "Poema sinfônico para 100 metrônomos", de György Ligeti: o aluno que nunca havia ouvido esse estilo musical pode apresentar repulsa em relação aos ruídos, à estrutura musical arrítmica, atonal, e ainda apresentar comportamento de estranhamento negativo, afirmando que isso não é música, pois considera como música necessariamente a presença de melodias cíclicas e a presença de texto verbal. Neste caso, o aluno não estabelece significado inerente e nem significado delineado havendo, portanto, a alienação em relação à música eletroacústica que não lhe gerou nenhum sentido.

Outro exemplo seria a ambiguidade dos significados quando da apreciação de uma peça de eletroacústica mista como "Jupiter" (1987), de Phillipe Manoury, que pode apresentar significado delineado positivo ao aluno que identificar o solo da flauta e associálo a um momento memorável da flauta sendo tocada em uma orquestra sinfônica, tendo, ao mesmo tempo, repulsa em relação ao material sonoro do live eletronics.

A ambiguidade dos significados também poderia ocorrer na apreciação de uma peça eletroacústica acusmática, como "L’oiseau chanteur”, de François Bayle, tocada numa sala de concerto na qual as luzes estão apagadas e o músico realiza execução da espacialização em tempo real. O ouvinte pode ter uma reação afirmativa em relação à sonoridade da peça que lhe é agradável por remeter à escuta de sons referenciais, porém, pode emitir uma reação negativa em relação à performance do músico e ao ritual, tendo em vista que o ambiente escuro não permitiu a apreciação visual da performance do músico.

Por fim, o último exemplo desse entrelaçamento dos significados musicais poderia ocorrer na celebração dos significados inerentes e dos delineados, quando o educador musical propõe a apreciação da peça “Oktophonie”, de Karlheinz Stokhausen, e uma 
criança advinda de uma família que ouve música eletroacústica e frequenta concertos acusmáticos e live eletronics cria sentidos em relação à sonoridade e à identificação social desta música de vanguarda.

Podemos responder positiva ou negativamente aos significados inerentes ou delinea-
dos. [...]A maioria dos educadores musicais provavelmente também concordaria que
a resposta dos alunos à música em sala de aula é tristemente indiferente. Os melhores
e mais inspiradores professores de música tendem a estar entre os primeiros a sugerir
que a educação musical não atinge todos os alunos. Muitos alunos têm experiências
"ambíguas", ou pior, experiências "alienadas", resultantes da negatividade em relação
aos significados inerentes e delineados de muitas músicas de sala de aula. As razões
não são simples.[...]A música é capaz de criar delineações novas e problemáticas den-
tro da sala de aula; o que por sua vez pode afetar negativamente as respostas aos seus
significados inerentes. Além disso, a familiaridade dos alunos com os significados
inerentes da música popular pode tornar-se desgostosa caso esses significados sejam
abordados de maneiras educacionais formais. Em resumo, mesmo a música popu-
lar tendo estado presente em sala de aula por muitos anos, a identificação com suas
delineações e familiaridade com seus significados inerentes não tem levado a expe-
riências de "celebração musical" para um esmagador número de crianças nas escolas.
Portanto, muitos alunos tendem a se encontrar em uma relação ambígua ou mesmo
alienada com muita música de sala de aula, mesmo quando é uma música celebrada
fora da escola (GREEN, 2012, p. 64-67).

Diante deste pensamento de Lucy Green, surge a possibilidade de se compreender como a educação musical pode abrandar a divisão entre música popular e clássica e como a própria sala de aula acaba modificando e complicando os significados musicais. Neste sentido, buscamos pensar tanto a presença da música popular quanto da clássica, sem estabelecer relação hierárquica ou de qualidade entre elas, mas no sentido de permitir aos alunos a experiência musical e a aprendizagem de novos repertórios, gerando novos significados e desenvolvendo autonomia e autenticidade na aprendizagem musical.

Tradicionalmente, a educação musical teve sua atenção voltada para o repertório do passado, adotando metodologias de ensino do passado. Ainda hoje, é comum observarmos práticas de ensino musical tecnicistas e reprodutoras de padrões descontextualizados e, ainda, equivocadamente, aplicadas a repertórios contemporâneos. No entanto, a antropologia pode nos fornecer subsídios para realizarmos uma educação musical voltada para a contemporaneidade, dentre eles, a relativização como forma de compreensão de processos e contextos culturais, na qual considera-se primeiramente o contexto de produção sociocultural como norteador de práticas. Relativizar é entender a lógica do contexto ao qual determinada música está inserida e, a partir da compreensão da teia de significados sociais e culturais em torno da música, conferir sentido às performances e didáticas. De acordo com Arroyo (2002), "A relativização implica que os processos e os produtos culturais só podem ser compreendidos se considerados no seu contexto de produção sociocultural" (ARROYO, 2002, p. 19).

A educação musical que se propõe a trabalhar a diversidade musical pode construir uma nova rede de significados mediante as possibilidades de influência mútua entre o contexto sociocultural, ao qual o aluno está inserido, e o repertório abordado pelo educador. Essa força semiótica é denominada por Tia DeNora ${ }^{6}$ (2000) como agency e affordance. Estes termos têm sido comumente traduzidos para o português como "agenciamento" e "fornecimento”, ações que se dão reciprocamente entre o ser humano e a música. 


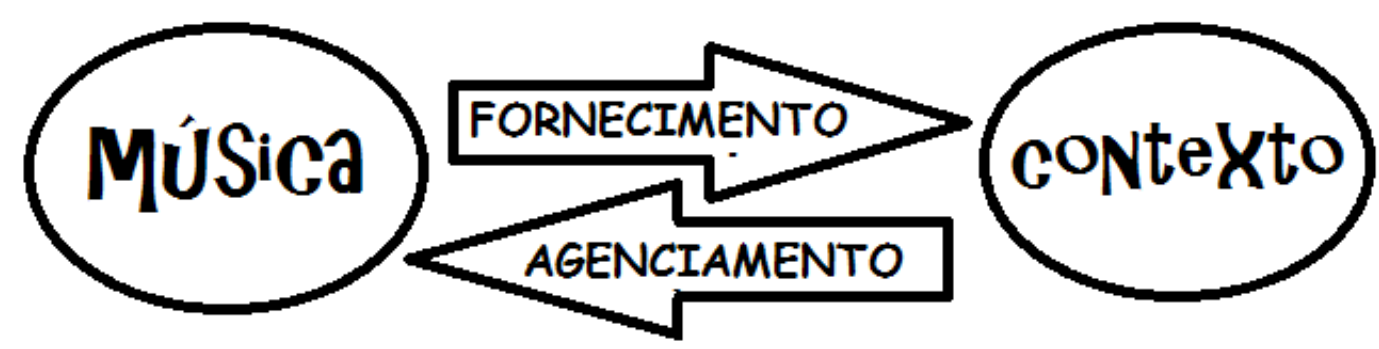

Figura 2: Relações de reciprocidade entre música e ser humano:

Agenciamento (agency) e fornecimento (affordance)

Fonte: Da autora (2016).

Tia DeNora estuda a presença da música na sociedade contemporânea e a sua capacidade de afetar a vida social. As ressignificações ocorrem tanto no âmbito musical quanto no extramusical. A música é ressignificada em cada contexto e isso se dá pelo processo denominado de agency, ou seja, o agenciamento. Simultaneamente, ocorre o processo contrário: o contexto passa a receber novos significados a partir do processo denominado de affordance, ou fornecimento, no qual a música oferece propriedades a partir das quais o ser humano investe significados.

O que mais importa não é o que a música significa, mas o que a música faz, o que ela provoca: "A interação humano-música transmite, então, a ideia de um movimento em duas direções, ou seja, a materialidade sonora age sobre o humano enquanto este a apreende de forma particular" (ARANTES, 2011, p. 51). Assim, as pessoas, em seus contextos, constituem e reconstituem significados, podendo isso ocorrer de maneira consciente ou inconsciente. Os diferentes significados gerados pela interação homem-música podem ser observados na influência da música eletroacústica sobre a música eletrônica pop, que ocorre nas técnicas de manipulação dos sons, na criação de novos timbres, na possibilidade de experimentar um som pela primeira vez e de desconstruir a noção de que música não precisa ser feita apenas com notas musicais e sim com frequências mais variadas. O timbre é um dos parâmetros do som mais importantes na música popular e isso é herança da música concreta, eletrônica e eletroacústica. Na relação entre a música eletroacústica produzida pelos músicos da vanguarda contemporânea e a música eletrônica pop tocada por DJs, concretiza-se a afirmação de que o fenômeno musical é universal. Todo ser humano tem a experiência musical da escuta e estabelece suas relações com a música e com outros seres humanos. Apesar das diferenças estéticas e funcionais da música eletroacústica e da eletrônica pop, ambas são produtos da musicalidade humana, produzidas por grupos sociais distintos em construção coletiva de significados e competências que desenvolvem seus modos particulares de escuta e performance musicais (STOCKFELD, 1997).

Se refletirmos sobre a apreciação musical eletroacústica, percebemos que os sujeitos não são livres no ato de ouvir. Para Stockfeld, as relações entre o ouvinte e a música determinam e impõem limites à escuta. Essas relações específicas de gênero entre a música e o ouvinte são situações de escuta de um gênero musical em determinado momento histórico. Concordes com a afirmação deste autor, consideramos que as experiências de aprendizagem da música eletroacústica podem se dar na escola, na sala de aula, numa sala de concerto e podem ser experiências individuais ou coletivas, com fones de ouvido ou ainda com sistema de som estereofônico da melhor qualidade. Entretanto, Stockfeld lembra que cada estilo musical tem seus modos adequados de escuta e que estes podem ser 
desenvolvidos pela educação musical.

Os modos de escuta são condicionados pela situação, pelo ambiente e pelos sujeitos. Assim, os encontros com a música condicionam o desenvolvimento de competências de escuta. Para Stockfeld (1997), cada sujeito ouve cada repertório de maneiras diferentes e estabelece competências distintas. Para tanto, o educador musical deve procurar oferecer possibilidades aos alunos de desenvolverem competências de escuta ao inserir em seu planejamento práticas musicais voltadas a diferentes repertórios musicais.

Ouvir adequadamente não significa, portanto, nenhuma maneira particular, melhor, ou "mais musical", "mais intelectual" ou "culturalmente superior" de ouvir. Significa que se domina e se desenvolve a habilidade de ouvir o que é relevante para o gênero da música, para o que é adequado à compreensão de acordo com o contexto compreensível do gênero em específico. A escuta adequada não é um pré-requisito para a assimilação ou o desfrute da música [...] (STOCKFELD, 1997, p. 91, tradução nossa).

Diferentes situações demandam ou tornam possíveis diferentes tipos de performance musical, o que gera diferentes modos de escuta e, consequentemente, diferentes experiências musicais. Isso não significa que ouvir adequadamente seja uma melhor, ou mais intelectual, ou mais musical forma de ouvir, no entanto, significa que cada gênero musical exige do ouvinte habilidade e maestria para compreender as especificidades do gênero, de acordo com seu contexto. Sendo assim, o educador musical precisa buscar a compreensão do contexto que envolve a música eletroacústica para, então, poder possibilitar uma escuta mais adequada aos alunos. Este é um tema de suma importância a ser melhor e mais intensamente investigado pelos educadores e pesquisadores musicais.

Na sala de aula de música na educação básica, estão presentes alunos que advêm de famílias com culturas distintas e que apresentam maior ou menor grau de experiências musicais, o que no leva a buscar metodologias que possam desenvolver um trabalho pedagógico eficiente e eficaz em classes heterogêneas.

Na década de 1990, houve grande efervescência de pesquisas em filosofia e sociologia da educação musical e também a utilização do termo práxis como resposta baseada em ação que vem em oposição à passividade e ao elitismo da educação musical proveniente dos séculos anteriores (ALLSUP, 2010). Práxis tem sua raiz na língua grega, da qual "prática" significa intersecção de um fazer intencional em um pensar intencional. Para Elliott (1995), a educação musical praxial preocupa-se com dois processos: a habilidade procedimental, que envolve a capacidade de fazer com destreza e está relacionada ao oficio de tocar um instrumento, e, paralelamente, o processo de pensamento musical, que consegue corresponder e representar uma tradição e é denominado musicalidade.

Se a musicalidade for compreendida pela abordagem antropológica, o educador entenderá que todas as pessoas têm a capacidade de fazer música e delineará suas práticas no sentido de possibilitar aos alunos que participem de performances musicais, em quaisquer níveis de capacidade que estejam, seja ouvindo ou executando, seja ensaiando ou praticando, seja compondo ou ainda dançando. A essas práticas, Christopher Small ${ }^{7}$ denomina musicking, forma ativa de os sujeitos se relacionarem com o mundo. Para Small (2009), a palavra música não pode ser entendida como substantivo e sim como verbo musicking. Desta maneira, o verbo 'musicar' é usado para expressar a ideia de fazer parte de uma ação musical e ainda como instrumento para interpretação da ação musical e de sua função na vida humana. 


\section{Apontamentos finais}

A proposta deste ensaio foi levantar elementos teórico-metodológicos da perspectiva sociocultural que possam sustentar práticas educativo-musicais e abordem o repertório musical contemporâneo, buscando, em especial, refletir sobre uma educação musical que contemple a música eletroacústica.

Há muito a ser estudado sobre as bases etnomusicológicas e sociomusicológicas. Pesquisadores nacionais e internacionais têm se dedicado a pensar diferentes temáticas que são fundamentais para fornecer sustentação a uma nova conjuntura na educação musical. Vejamos os principais temas e autores que foram base para este trabalho e que podem ser pesquisados para maior aprofundamento: cultura como teia de significados (GEERTZ, 1989); os processos e produtos musicais e o conceito de musicking (SMALL, 2009); sobre a interação humano-música (DENORA, 2000); em relação ao gosto em música (HENNION, 2011); sobre a experiência musical da escuta (STOCKFELD, 1997); sobre significados musicais (GREEN, 1997; 2012). Em relação ao pensar e ao agir do educador musical diante das demandas contemporâneas, podem ser pesquisados autores como: Allsup (2010), sobre a filosofia da educação musical; Elliott (1995), sobre a abordagem praxial; Jorgensen (1997), sobre a abordagem dialética.

Além desses autores, outros subsidiam nossa leitura, principalmente aqueles que se preocupam com a dimensão social e cultural da educação musical. Neste intento, destacamos a afirmação de Swanwick sobre o foco da educação musical, a qual deveria:

[...] colaborar para que jovens e crianças compreendam a música como algo significativo na vida de pessoas e grupos, uma forma de interpretação do mundo e de expressão de valores, um espelho que reflete sistemas e redes culturais e que, ao mesmo tempo, funciona como uma janela para novas possibilidades de atuação na vida (SWANWICK, 2016).

Revendo as práticas educativo-musicais pelo viés teórico-metodológico sociocultural, vislumbramos uma educação musical que não impõe padrões; que adota a concepção de música como ação social e valoriza a musicalidade do aluno; que não avalia determinada música pelos critérios de outra música; que admite aprendizagens informais e formais e constrói práticas musicais a partir de novas aprendizagens; que torna-se um espaço de ampliação dos sentidos e media a musicalidade do outro; que valoriza o aprender música fazendo música; e entende a importância do cantar, do tocar e do ouvir diferentes repertórios pela abordagem da relativização contextual.

\section{Notas}

1 Clifford Geertz (1926-2006) foi um antropólogo estadunidense, professor emérito da Universidade de Princeton, em Nova Jersey, nos Estados Unidos. Seu trabalho no Institute for Advanced Study, de Princeton, se destacou pela análise da prática simbólica com olhar antropológico. Foi considerado, por três décadas, o antropólogo mais influente nos Estados Unidos.

2 Michel Maffesoli (1944 - ), sociólogo francês conhecido sobretudo pela popularização do conceito de tribo urbana. A obra de Michel Maffesoli tem se destacado por tentar compreender o homem dito comum sem menosprezá-lo como algo insignificante, se comparado ao pesquisador de formação acadêmica. E isso não é pouca coisa, principalmente pelo histórico de Maffesoli: professor da sisuda Sorbonne. Ele é autor de livros corajosos, questionando o que chama de moralismo judaico-cristão (de forte inspiração nietzschiana) da sociedade ocidental. O "ocidentalismo" como suporte identitário é o que está na base do pensamento maffesoliano (BARROS, 2008).

3 Estelle Jorgensen (1945 - ) é professora emérita de Música (Educação Musical) na Escola Jacobs Indiana University of Music e editora de filosofia de Educação Musical. Publicou vários livros de filosofia, ensino e música: Contemporary perspectives on music education (1993), In search of music education (1997), Transforming music 
education (2003), The art of teaching music (2008) e Pictures of music education (2011), e inúmeros artigos em importantes revistas de educação musical internacionalmente.

4 Marie McCarthy é especialista em música geral. Seus estudos de investigação centraram-se nas bases socioculturais e sócio-históricas da educação musical, em particular o estudo da transmissão de música, a relação entre os processos de ensino da música em contextos formais e aqueles na cultura em geral, bem como o impacto da educação musical no desenvolvimento de identidade em contextos individuais e coletivos.

5 Lucy Green (1957 - ) é professora de Educação Musical na UCL Institute of Education. Estuda as práticas de aprendizagem informal da música popular, contribuindo para transformar a prática em sala de aula. Seu trabalho também tem sido influente em outras áreas da sociologia da educação musical, particularmente em relação ao gênero, significado musical e ideologia e pedagogia música popular.

${ }_{6}$ Tia DeNora (1958 - ) é professora de Sociologia da Música e diretora de pesquisa do Departamento de Sociologia / Filosofia na Universidade de Exeter. Suas principais publicações são: Making sense of reality culture and perception in everyday life (2014); Music Asylums: Wellbeing Through Music in Everyday Life (2013); Music-in-action: essays in sonic ecology (2011); After Adorno: rethinking music sociology (2003); Music in everyday life (2000).

7 Christopher Small (1927-2011), músico, educador neozelandês, autor de vários livros e artigos influentes nas áreas de musicologia, sociomusicologia e etnomusicologia. Ele cunhou o termo musicking (musicando), com o qual queria destacar que a música é um processo (verbo) e não um objeto (substantivo). Autor de Música, sociedade e educação (1977); Music of the common tongue: survival and celebration in African American music (1987); Musicking: the meanings of performing and listening (1998)

\section{Referências}

ALLSUP, Randall. Philosophical perspectives of music education. In: ABELES, Harold F.; CUSTODERO, Lori A. (Ed.). Critical issues in music education. New York: Oxford University Press, 2010. p. 39-60

ARANTES, Lucielle Farias. “Tem gente ali que estuda música para a vida!”: um estudo de caso sobre jovens que musicam no projeto social Orquestra Jovem de Uberlândia. 2011. 244 f. Dissertação (Mestrado em Artes) - Instituto de Artes, Universidade Federal de Uberlândia, 2011.

ARROYO, Margarete. Educação musical na contemporaneidade. In: SEMINÁRIO NACIONAL DE PESQUISA EM MUSICA DA UFG, 2, 2002, Goiânia. Anais... CD-ROM. p. 18-29.

Pensando a educação musical imaginativamente: uma filosofia da educação musical por Estelle Ruth Jorgensen. Per Musi, Belo Horizonte, n. 27, 2013.

CUNHA, Daiane Solange Stoeberl da; GOMES, Erica Dias. Música e transformação: por um olhar diferenciado na história da música. Guarapuava: Unicentro, 2014.

CUNHA, Daiane; GALLO, Helen. Aspectos da música eletroacústica mista: tecnologia, transformação estética e interatividade. Revista Científica FAP., v. 10, n.1, p. 115-134, jan./jun. 2014.

BARROS, Eduardo Portanova. Maffesoli e a “investigação do sentido” - das identidades às identificações. Ciências Sociais Unisinos, v. 44, n. 3., set./dez. 2008.

BORGES, Alvaro. O compositor na sala de aula: sonoridades contemporâneas para educação musical. 2014. 121f. Tese (Doutorado em Música) - Instituto de Artes, Universidade Estadual Paulista, São Paulo, 2014.

DENORA, Tia. Music in everyday life. Cambridge: Cambridge University Press, 2000.

ELLIOTT, David. Music matters: a new philosophy of music education. Oxford: Oxford University Press, 1995.

FONTERRADA, Marisa Trench Oliveira. De tramas e fios: um ensaio sobre música e educação. 2. ed. São Paulo: UNESP; Rio de Janeiro: FUNARTE, 2008.

GEERTZ, Clifford. A interpretação das culturas. Rio de Janeiro: Guanabara/Koogan, 1989. 
GREEN, Lucy. Pesquisa em sociologia da educação musical. Trad. Oscar Dourado. Revista da ABEM, Salvador, n. 4, p. 25-35, 1997. Disponível em: <http://www.abemeducacaomusical.org. br/Masters/revista4/artigoII.pdf>. Acesso em: 10 maio 2005.

GREEN, Lucy. Ensino da música popular em si, para si e para 'outra música': uma pesquisa atual em sala de aula. Revista da ABEM, v. 20, n. 28, p. 61-80, 2012. Disponível em: <http://www. abemeducacaomusical.com.br/revistas/revistaabem/index.php/revistaabem/article/view/104>. Acesso em: 12 fev. 2014.

HENNION, Antoine. Pragmática do gosto. Desigualdade \& Diversidade - Revista de Ciências Sociais da PUC-Rio, n. 8, p. 253-277, jan./jul. 2011.

JORGENSEN, Estelle R. In search of music education. Urbana: University of Illinois Press, 1997. KOELLREUTTER, Hans-Joachim. Terminologia de uma nova estética da música. 2. ed.

Porto Alegre: Editora Movimento, 1990.

MAFFESOLI, Michel. Saturação. São Paulo: Iluminuras/Itaú Cultura, 2010.

McCARTHY, Marie. Introduction. Social and cultural contexts of music teaching and learning. In: COLWELL, R.; RICHARDSON, C. The new handbook of research on music teaching and learning. Nova York: Oxford University Press, 2002. p. 563-565.

REIBEL, Guy. Jeux musicaux. Jeux Vocaux. Paris: Salabert, 1984. v. 1.

SCHAFER, R. Murray. Educação sonora: 100 exercícios de escuta e criação de sons. Trad. de Marisa Fonterrada. 2. ed. São Paulo: Melhoramento, 2009.

. A afinação do mundo. Trad. de Marisa Fonterrada. 2. ed. São Paulo: UNESP, 2011a.

. O ouvido pensante. Trad. de Marisa Fonterrada. 2. ed. São Paulo: UNESP, 2011b.

SMALL, Christopher. El musicar: un ritual en el espacio social. Revista Transcultural de Música, Barcelona, n. 4, 1999. Disponível em: <www.sibetrans.com/trans/index.htm>. Acesso em: 10 fev. 2009.

STOCKFELD, Ola. Adequate modes of listening. In: SCHWARZ, David; KASSABIAN, Anahid; SIEGEL, Lawrence (Ed.). Keeping score: music, disciplinarity, culture. Charloteesville, Vi.: University Press of Virginia, 1997. p. 129-146.

SWANWICK, Keith. Keith Swanwick fala sobre o ensino de música nas escolas. 2011. Disponível em: <http://acervo.novaescola.org.br/arte/fundamentos/entrevista-keith-swanwick-sobre-ensino-musica-escolas-instrumento-musical-arte-apreciacao-composicao-529059.shtml>. Acesso em: 20 nov. 2016.

VERTAMATTI, Leila. Rosa Gonçalvez. Ampliando o repertório do coro infanto-juvenil: um estudo de repertório inserido em uma nova estética. São Paulo: UNESP, 2008.

Daiane Solange Stoeberl da Cunha - Doutoranda em Música no Programa de Pós-Graduação em Música da Universidade Estadual Paulista. Bolsista CNPq. Mestra em Educação pela Universidade Federal do Paraná, na linha de pesquisa Saberes e Cultura, com dissertação intitulada Educação Musical e Emancipação: A Formação do Educador Musical a partir de uma perspectiva crítica. Graduada em Pedagogia pela Universidade Estadual do Centro-Oeste (UNICENTRO). Especialista em Música Eletroacústica com ênfase em Composição pela UNESPAR- FAP. Docente no curso de licenciatura em Arte da UNICENTRO. 